\title{
Sciendo
}

Administration, vol. 68, no. 4 (2020), pp. 181-199

doi: 10.2478/admin-2020-0030

\section{Implementing choice-based models of social service: The importance of involving people who use services in reform processes}

\author{
John Healy \& Madeleine Clarke \\ Genio, Ireland
}

\begin{abstract}
This article focuses on the opportunities and challenges of introducing choicebased models of social services. Research has found that these models often provide better outcomes and are cost-effective, but the pace of their introduction is generally slow. There are often very deeply held assumptions about the capacity of the people using these services and the potential for change within the existing social service system. Using institutional and social movement theory, the authors seek to explain these barriers to change. Drawing on the experience of supporting the national roll-out of choice-based models in Ireland, the authors propose a number of strategies to accelerate the introduction of these types of models into social services. The authors find that one of the key ways to accelerate reform and reduce transition costs is design processes which have the voice of service users at the centre of the reform process.
\end{abstract}

Keywords: Social services, reform, choice, co-production, lived experience 


\section{Introduction}

In this article we explore the efforts to introduce models of social services with greater choice for people using these services. The article focuses on how the challenges involved in implementing reforms can be overcome. Based on our experiences of supporting social service reform efforts in Ireland over the last ten years, we discuss the opportunities and challenges involved in supporting social services to move from more traditional 'one size fits all' to more choice-based models or 'self-directed' models. These are social services where the person using the service has a significant influence over the type of service they receive. Co-design processes are now taken for granted in the commercial realm, where producers of goods and services increasingly seek input by consumers into design processes (Bettencourt et al., 2002). As we outline below, research has found that giving social service users choices tends to be more effective and is often less expensive. Self-direction and choice have become central features of espoused government policies across Europe. Despite this, social service systems have been slow to adopt these models. Drawing on previous research and our own experience of supporting the implementation of service reforms, the questions we address are 'What are the main barriers to implementing change to social service models based on greater service user choice, and how can these barriers be overcome?' To answer these research questions we draw on a combination of institutional and social movement theory to help inform and ground the analysis.

The article starts with a brief discussion of choice-based concepts in social services and examines conceptually how these more choicebased services differ from traditional social services. The paper then moves to introduce the Irish context. We explain briefly the role of the Genio non-profit organisation in supporting social service reforms and highlight three examples of models of choice-based social services that have been introduced in Ireland. International and national evidence regarding these models' efficacy and costs is outlined. We then move to a discussion of the challenges of moving from a traditional service model to a more choice-based model. A key focus of the analysis is on the drivers of the costs of moving from the traditional model to a choice-based model. Institutional theory is used to explain why services that are tasked with reforming themselves often take longer and implement change with higher costs. Social movement theory is used to explore how having greater involvement by people using 
services in the process of changing services speeds up the change process and reduces costs.

The central contribution of the article is to outline the implementation opportunities and challenges for those seeking to introduce greater levels of choice in social services, and to propose strategies to overcome these challenges.

\section{The rise of lived expertise and choice in social services}

The idea that people using services should have choice and be involved in shaping services is not new. The slogan 'Nothing about us without us' emerged from the disability field in the 1990s to wider use in social movements seeking to challenge exclusion of groups from decisionmaking. The movement of people using social services and supports advocating for greater involvement in shaping the nature of the services and supports they receive has deeper roots running back to the 1970s. According to Clark (2015), co-production arose from frustrations that, despite transitioning from institutional models of care to community-based services, there had been a failure to actually shape these services around the preferences and needs of service users. In the UK an influential report by the Healthcare Commission in 2005 found that services were designed in many instances around the needs of staff rather than patients (Bate \& Robert, 2006; Healthcare Commission, 2005). In many cases, there were concerns that community-based care had replicated many of the paternalistic attitudes of institutional models of care (Bate \& Robert, 2006; Clark, 2015). Whilst there are debates around the appropriate definition of co-production, the essence of the concept is that there is a recognition of the experience, capacity and insights of the person using the service. Services are then discussed and agreed based on an equality of power between the person using the service and the person providing it. Figure 1 shows a hierarchy of levels of service user engagement proposed by Bate \& Robert (2006, p. 309).

Conceptually, there is also a need to be clear about the role and purpose of people in co-designing services (Clark, 2015; Needham et al., 2012; Realpe \& Wallace, 2010). At the level of the individual receiving services or supports, co-production changes their role from passive receiver to providing capacity, insight and experience into how the individual service they receive can be best shaped around their expressed needs and preferences. This has required a significant reshaping of the nature of the relationships between these individuals 


\section{Figure 1: A hierarchy of service user involvement}

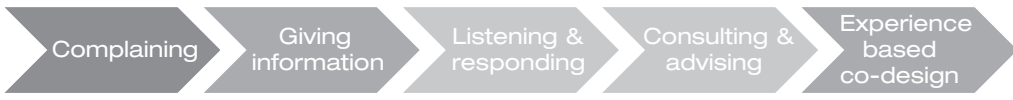

and the professionals, staff, and public, private and NGO organisations with which they interact. Also, the movement for greater co-creation of services has moved well beyond the concept of individuals renegotiating roles with professionals. Despite much tokenistic involvement, the lived experience of people who have used services has influenced the management and governance of social service systems (Realpe \& Wallace, 2010). At a practical level this might mean voluntary participation by people who have used services on advisory groups, assessment committees for the allocation of resources and other governance structures. Increasingly, people with lived experience are being recognised as having a professional contribution to make in the delivery and management of services as peer worker and engagement leads across a range of fields such as homelessness, mental health and addiction.

\section{The Irish context}

In addition to these professional and voluntary roles in service design and management, people using social services are also best positioned to highlight the importance of implementing reforms in a timely fashion. In Ireland much progress has been made in introducing more person-centred policies and transitioning from institutional models of care to more community-based services. Policy documents such as Time to Move on from Congregated Settings (Health Service Executive, 2011), Vision for Change (Department of Health, 2006), Sharing the Vision (Department of Health, 2020), the Irish National Dementia Strategy (Department of Health, 2014) and Rebuilding Ireland (Government of Ireland, 2016) all share a commitment to provide a more central place for people to shape the services they receive.

That said, there have been significant challenges to implementing these ambitious policies. It should also be remembered that over 2,000 people with disabilities still live in congregated settings, where supports are often group-based and choice is limited. In 2019 the Mental Health Commission found that 1,200 people with severe 
mental illnesses are at risk of abuse, having been left in 'miniinstitutions with little prospect of receiving rehabilitation' into community living. As we outline below, this is not surprising. Change does not happen simply because compelling evidence says there is a better way, or because concepts become enshrined in policy. There is a significant body of research on organisational change and systems change to indicate that designing ambitious policy and providing resources are necessary, but that there are often insufficient conditions for changing models of support and practices in social services. There is a need to be realistic about both opportunities and challenges for implementing change.

Genio is a non-profit organisation that supports social services to move from traditional, congregated models of support to more choicebased models. Genio adopts an action research model to support complex social service systems engaging in reforms. Since the organisation was founded in 2010 it has supported change programmes across disability, mental health, homelessness, addiction and dementia in Ireland. Genio is part of the Service Reform Fund, a €45-million fund established with the Department of Health, the Department of Housing, Local Government and Heritage, the Health Service Executive, the Dublin Regional Homelessness Executive and the Atlantic Philanthropies towards more choice-based models. In 2019 Genio partnered with the European Commission, the Robert Bosch Foundation and the King Baudouin Foundation to establish the European Social Catalyst Fund to help scale choice-based innovations in social services across the EU.

In our experience, there is often very real frustration and anger felt by people using services that the actual services they receive are far removed from espoused policy, which often describes choice-based models. It is usually not a lack of courage on the part of senior administrators that leads to the retention of inappropriate models and practices. Often those administering and delivering social services recognise this gap between policy and practice but they feel trapped in the status quo. Unable to publicly acknowledge the difficulties of changing social services, they devote much of their time and budgets to managing emergency cases, leaving little space to promote the new model of practice. These emergencies can come in the form of abuse scandals, regulation breaches or legal cases; all of which require immediate attention and resources. Oftentimes, there are two systems that they are managing: a larger, traditional service and a smaller, emerging model. In Ireland service provision can become trapped 
between these two stools, unable to progress in a coherent way towards implementing new, more progressive models of practice. Overtime, this situation can become an assumption that the new policy cannot be implemented and costs spiral as reactive, fragmented emergency provision becomes commonplace. As we outline below using Irish examples, having a coherent implementation strategy which practitioners in the field can adopt to make progress towards new policy is key. The perception of the costs of transition by service providers within these systems and those funding them is one of the key barriers to successfully transitioning from pilots and demonstration projects to systemic change.

Looking to the future in Ireland, demands for greater choice and involvement are likely to grow and to be reinforced by litigation. The Assisted Decision Making Act and recent ratification of the UN Convention on the Rights of Persons with Disabilities have presented those who implement policy with an urgent need to transform the ways in which social and health services and supports are delivered. Although there is significant planning and advocacy work involved in designing and enacting laws and policies, it is at the level of implementation of services and supports that the role of the citizen using services is most critical. There is a strong track record of designing ambitious policies enshrining the goal of citizen-centred services in a range of social care and health fields. This has not been mirrored by clarity about how these policies will be implemented or how new rights will be justiciable. The Assisted Decision Making Act, in particular, is likely to create a strong impetus for change in terms of how social service reform is implemented. The Act makes it a legal requirement that service providers and professional groups assume capacity in the people that they are supporting. Having a gap between policy and practice creates frustration and anger. It is a significant milestone in the development of more personalised services in Ireland and, once the Assisted Decision Making Act is fully implemented, it will create a pressure for choice to be more central to services and supports.

From the Irish context then we can see that the pressure for choicebased models in social services is likely to follow the international trend and grow over the coming years. Before moving to discuss implementation challenges, we discuss three examples of choice-based social services which have been introduced in Ireland and what can be learned from the efforts to introduce these changes. 


\section{An overview of three models of choice-based social services}

In order to set up a realistic analysis of the potential for services to be transformed we focus on three models which put the choice of the person at the centre of provision and which are being implemented at a national level in Ireland: Housing First, Community Living and Individual Placement and Support (IPS). The purpose of introducing these examples is to analyse whether salient lessons can be drawn from the national roll-out of change programmes from traditional, groupbased approaches to service provision to more choice-based models of support. We explain below that whilst the international evidence for these models is convincing, there was still a need to develop a realistic implementation plan for how these three models of practice would be integrated and bring change within the existing systems.

\section{Housing First}

Housing First is a service which supports people who have been longterm homeless, often with complex addiction and mental health challenges, to move into their own home. It is an alternative to the approach of 'managing' homelessness through emergency shelters and hostels. Housing First seeks instead to end homelessness by supporting people to access and maintain tenancies. It is based on a model which was first introduced in the US and Canada but which has become more widespread in Europe over the past decade. One of the key distinctive features of the Housing First model is that it is clientled and there are no preconditions for accepting people on the programme. The individual chooses the timing, nature and extent of services offered, and support staff work to provide the greatest choice possible regarding where the person decides to live. Housing First works to support the recovery and social integration of the people on the programme. Housing First was introduced as a pilot in Dublin in 2011 and has grown over the last nine years and has now been rolled out nationally.

\section{Community Living}

Community Living supports people with disabilities to progress from living in large congregated settings to lives of their choosing in mainstream community settings. The Value for Money and Policy Review of Disability Services report recommends that the goal of full inclusion and self-determination for people with disabilities be pursued 'through access to the individualised personal social supports 
and services needed to live a fully included life in the community' (Department of Health, 2012, p. xxviii). Although approaches vary, the most personalised supports involve an in-depth discovery process carried out with the person and loved ones to explore where they would like to live, with whom they would like to live, and what aspects of social life and employment they would like to develop. This approach can be contrasted with other approaches which seek to decant people from institutions into smaller residential institutions in the community that do not build in an approach to discover and respond to their will and preference.

\section{Individual Placement and Support (IPS)}

IPS is an evidence-based approach to employment for people who have a severe mental health difficulty. IPS has now been introduced as part of mental health services in European countries as well as the Americas and Asia. IPS supports people in their efforts to achieve steady employment in mainstream competitive jobs, either part-time or full-time. This can be contrasted with other vocational rehabilitation approaches that employ people in sheltered workshops and other similar-type interventions. Unlike traditional approaches, IPS does not require a person to be 'job ready'. The main criteria for participation in the IPS programme are that there is a genuine desire and motivation to seek employment and that the supports are directed by the person. IPS has now been rolled out across all of the community healthcare organisations of the Health Service Executive and the National Forensic Mental Health Services.

\section{Overview of evidence on effectiveness and costs of models of choice-based social services}

It is often assumed that choice-based services must be more expensive. Intuitively, it would seem to stand to reason that a group-based service should be cheaper, with economies of scale within one large congregated facility or group-based service. The problem with this analysis is that it is anecdotal and not based on the actual research. It does not explore the dynamic picture of what happens to the people being supported. A more sophisticated analysis of the evaluative evidence paints a very different picture.

In the case of Housing First, for example, the model is shown to be twice as effective as traditional approaches. In Ireland findings indicate an efficacy rate of $80-5$ per cent (Greenwood, 2015). This 
contrasts with an efficacy rate of approximately 50 per cent in more traditional services. The international evidence on the effectiveness of IPS compared to standard approaches is compelling. A Cochrane systematic review found that IPS was more effective than other approaches in helping individuals to gain and retain competitive open employment (Crowther et al., 2001). The longitudinal effectiveness of the approach has been shown in follow-up studies after eight to twelve years (Becker et al., 2007; Salyers et al., 2004). In terms of costeffectiveness, people supported into open employment through an IPS approach worked significantly more hours per month, had higher average earnings and had better job tenure (Crowther et al., 2001; Drake et al., 1996, 1999; Mueser et al., 2004). In terms of community living, an expert group working for the European Commission (2009) found that there is 'strong evidence in support of transition from institutional care to community-based alternatives'. McConkey et al. (2013, pp. 115-16) found, based on a comprehensive analysis of people being supported to move from congregated institutions in Ireland, that evidence points 'towards personalised arrangements producing better outcomes for the people supported, irrespective of their impairments and level of functioning, than for those who continued to live in congregated settings or in group homes'.

The common themes of choice and co-production running through these three models suggest that the emphasis on involving the individual in the process of shaping the service they receive not only makes the service more in line with what they want but also adds to the efficacy of the supports they receive. It would seem that part of the reason for the efficacy of these models over more provider-centric models is the ways in which they enable aspects of the locus of control to be with the person using the service. The cost-benefit analyses which have been carried out on these models also find that costs tend to be either cheaper than or comparable with the traditional service provided (Knapp et al., 2013; Latimer et al., 2019; McConkey et al., 2013).

As we can see, from both rigorous international evidence and the evaluation of demonstration projects, these models not only deliver greater choice to people in line with stated government policy but also are more effective and potentially provide better value for taxpayers.

This then raises questions about implementation. What barriers does the implementation of models which 'work in the abstract' face and how best should these be circumnavigated? As we outlined in the introduction, the worst-case scenario is that the social care systems 
become stuck between the new, choice-based, less expensive models and the more traditional, provider-centric models. In this situation, not only does it negatively impact people using traditional services but costs spiral and the risks to administrators of attempting to implement change grow. The main challenges to implementing more choicebased models are outlined in the next section below. We then conclude by outlining some suggestions for how best to introduce these types of changes into complex social care systems.

\section{Challenges to introducing choice-based models}

The challenges of introducing models such as those described above are now discussed. One of the biggest difficulties to introducing significant change into large-scale, complex systems is that it can often seem extremely challenging at the outset. All of the models referenced above require multiple health and social services to integrate in order to support the individual. Often it is the very people who have been tasked with managing emergency cases and crises of the existing system who are mandated to introduce the new choice-based social services. Institutional theory holds that cognitively people develop ingrained beliefs and practices in the way that they perceive problems and solutions (Barley \& Tolbert, 1997). That is, they develop fixed, taken-for-granted assumptions about what kind of changes are possible within systems.

In many services there are histories of lack of cooperation between departments and divisions, and there are often ingrained beliefs and practices built around the status quo. Ambitious policies often carry little weight with administrators who are struggling under the burden of managing urgent crises, and can engender a sense of 'pity the fool' who tries to implement policy. In these situations people tend to get rewarded for an ability to manage the crises, grow budgets and maintain a defensible position between espoused policy and reality of the current model (Argyris, 2002), rather than seeking to change the operating model. The ingrained beliefs and practices associated with the status quo become 'taken for granted' (Barley \& Tolbert, 1997; Scott et al., 2000; Zucker, 1991) and also become part of the collective identities of the professional and staff groups (Glynn, 2000; Greenwood et al., 2002) delivering the traditional services. The important point is that the service provision system can itself become 'institutionalised' at all levels of the hierarchies involved. In certain services, acknowledging capacities and expertise of people using 
services can be seen, often unconsciously, by staff and professional groups as displacing their expertise. Often, it is not that people are resisting change; they are instead defending a status quo without even knowing it. Where the services are dominated by emergency service provision, providers can see themselves as holding a very thin line between some level of service and chaos. Also, many have little experience of witnessing the capacity of service users. Their lived realities are often as follows:

- services are fragmented across departments and constantly being restructured;

- policy is well intentioned but un-implementable;

- the people using services do not have the capacity to direct the services they provide and service providers do not have the resources to deliver these services.

The lived reality for these staff and professionals is that they see the people using services in dependent roles and, despite the international evidence, there is often the refrain, 'Well, that wouldn't work for the people we support.' In introducing new models into services that have been proven to be more effective and to be less expensive, the problem is often that the costs of transitioning from model A to model B are not objective. That is, the actual costs depend to a large degree on how the actors within the systems have constructed the barriers to transition and what it will cost to circumnavigate these barriers. The longer that all of the various provider groups take to decide what is needed to move from model A to model B, the more costs will increase. The pace of change decreases as each group's institutionalised attachment to the status quo is negotiated, with many of the staff and professional groups deeply unconvinced about the merits of choice and the capacity of service users to shape the services they receive. This can often lead to parallel services being run in tandem with increased, rather than reduced, costs. Figure 2 illustrates how the institutionalised, taken-for-granted assumptions of those running the current system drive the increased costs of the transition and elongate the process.

The irony of the above process is that the voice of the people for whom change matters most - those using the service - is often not represented in a powerful way during the implementation of these transitions. Sometimes the people providing services are seen by the public as proxies for the voices of those using them. The transition 
Figure 2: Transition costs and time frame when incumbent providers shape process

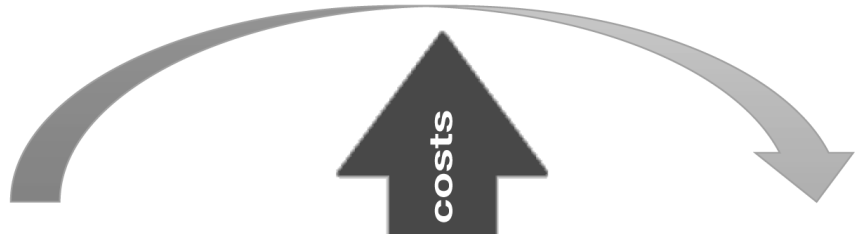

Model A

\section{Time}

between services can last for decades, during which time they do not receive services which reflect their will and preference and the taxpayer has to fund two parallel models. This is often in the context where transitions are implemented by managers and staff who have been institutionalised in the 'Model A' beliefs and practices. Senior managers often find it extremely challenging to remove themselves from the framing of problems through a very traditional lens. This is partly because their own world view has been cognitively ingrained but also because they can be under pressure from medical professionals, unions, legal cases and regulatory authorities to maintain the status quo.

\section{Making change possible within social service systems}

We now move to discussing how the barriers to implementing choicebased models can be overcome. The following are some themed reflections from recent efforts in the housing, disability and mental health fields to change systems, which have made progress despite significant implementation challenges.

Harnessing the power of the voice of those people using services As outlined above, according to institutional theory, introducing change to systems where the incumbent actors design the change 
process will be costly and slow. Research on introducing change into complex systems where there are existing ingrained beliefs and practices highlights the need for conscious efforts to understand the system and effect change (Lawrence et al., 2009; Zietsma \& Lawrence, 2010). According to social movement theory, grounding systems change in the expressed will and preference of people being supported by the social services is one of the most powerful ways to change the dynamics of a field (Bate et al., 2004). The most obvious way to do this is by social services putting in place objective, rigorous processes to gather feedback on both the traditional and new services. This feedback can then be brought into dialogue with other stakeholder groups, but not on an equal footing. It should be agreed at the outset that those receiving the service are best placed to give guidance on whether the service is meeting their will and preference.

A powerful way to instigate changes in institutionalised beliefs and practices is to involve people with lived experience of the social challenge in powerful positions in an advisory capacity, in particular funding committees which allocate resources for reform. In our experience this models the change that you are seeking and provides fresh insights into reform strategies. Perhaps as importantly, it creates a symbolic shift in power from professionalised staff groups towards people using services, if the advice and guidance provided is taken seriously and acted upon. Also, employing peer workers on a professional basis to work alongside more traditional roles, with clear mandates and specific roles, can bring not only a way of modelling hope and recovery to people using services but also a way of challenging the views of people as dependent and lacking in capacity (Davidson et al., 2012). A systemic review of the impact of peer workers in the mental health field found that their contribution to recovery was similar in efficacy to that of professionals employed in similar roles (Pitt et al., 2013).

All of these processes need to be designed carefully and the 'table needs to be set' for constructive discussions. Effort needs to be put into communicating the stories of individual change. The most compelling evidence is often where a sceptic witnesses significant change and the revealing of significant capacity in people who were thought to be dependent. There are plenty of examples of professional staff witnessing dramatic changes in people as they flourished through social integration and employment across IPS, Community Living and Housing First. These staff become firm converts to the new model. It is important to capture the narrative stories from these people using 
services and from the staff and share them purposefully (Bate et al., 2004).

\section{Employ a rigorous process to surface, discuss and solve problems during implementation}

As outlined above, creating an elaborate blueprint in the policy realm and assuming that actual social services can adapt quickly towards implementing this blueprint is usually a recipe for frustration. Having an implementation strategy which can adapt as challenges emerge is key (Grint, 2005). There are many significant implementation challenges which need to be made 'discussable' before they can be addressed. The action research approach used by Genio focuses on interviewing people in small groups or individually to surface the underlying problems. Then the approach employs the wisdom in the room to address implementation challenges as they emerge (Coghlan, 2017). It enables everyone to quickly see how interpreting problems can help parse out the different components that need to be addressed. Some challenges are beyond the scope of the individual reforms and it is important to identify who has found workaround solutions or ways to mitigate these challenges so that the focus of discussions do not get enmeshed in issues that are unlikely to be addressed (Marsh et al., 2004). In one of the change processes that Genio supported, one leader referred to advice he offered staff at the outset: to focus on the 'four foot square around them'. That is, to begin taking action and changing practice within the areas which they have control over. Making the tasks of reform practical allows the process to get traction and develop momentum. In most cases people act their way into reform rather than thinking their way through (Weick, 1979; Weick et al., 2005). Initially in change processes, most people want to know if the effort is for real or like previous efforts where reviews were commissioned, pilots funded and/or the organisational chart was restructured. It is important to engage early in implementation action.

\section{Making everyone responsible for making specific decisions}

In addition to the strategies of using the power of service user voice and action research, it is vital to have an approach to leadership which balances the need to create pressure to move towards the new model of practice without overstressing the system. This requires leaders to adopt an adaptive approach to implementing reform during complex change processes, iterating between 'getting up on the balcony' to gain a strategic perspective on the wider change effort (especially the 
expressed views of those using services) and exploring the challenges faced by frontline staff (Heifetz, 1994; Heifetz \& Laurie, 2001). Adaptive leaders need to ensure that problems do not fall between departmental stools or that situations develop where everyone is responsible, and therefore no one is responsible. Allocating specific responsibilities for delivering change needs to be part of the process, particularly at the outset of complex reforms, when there can be strong incentive to 'watch and see' rather than to start implementation (Heifetz \& Laurie, 2001). The three cases of service reform that we outlined - IPS, Housing First and Community Living - involved complex implementation discussions across multiple agencies, where staff often acted courageously to implement reforms under conditions of uncertainty. A vital component of this work is having leadership at the centre of the process that recognises and values data about emerging challenges but that also clearly allocates and takes responsibility for addressing these challenges. Figure 3 highlights how these three approaches to implementing choice-based models of support can accelerate the change for people using services and reduce the transition costs.

Figure 3: Transition costs and time frame when service user voice is at the heart of a reform process

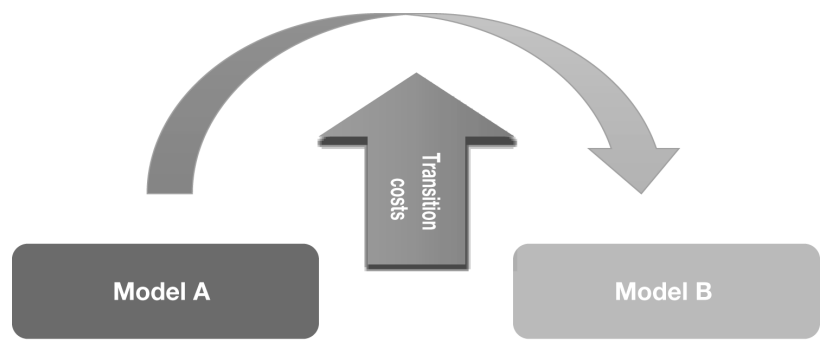

Time

\section{Conclusions}

Overall, there has been progress in introducing more choice-based models to Ireland but there is still a significant distance to travel to making choice-based models a central feature of social service delivery and design. Although these types of choice-based models 
have compelling evidence in terms of efficacy and cost, there are very real challenges with introducing them into existing social service systems. As outlined above, one of the most significant challenges is that those leading the design and delivery of these systems are often consumed with managing day-to-day crises of the current system and often there are deeply held assumptions around the difficulties of introducing reforms. Involving people using services and those with lived experience of the particular problem being addressed in the transition process is not only the right thing to do from a rights perspective; it is also often the most cost-efficient way to deliver services which align with the will and preferences of those using them. In addition, from a systems change and social movement theory perspective, involving these voices centrally in the change process is often the best way to accelerate the change. It helps ensure that resources can be moved from more traditional models to more progressive, personalised services, and that the field does not get stuck with two parallel services running to satisfy the various interest groups involved.

These processes need careful design and should be based on what we know about how services actually change, rather than heroic assumptions about how change can be implemented. In particular, there is a need to acknowledge the barriers that exist within fields and to design processes which enable staff and professionals to redefine their roles in ways that support models putting the people using the service at the heart of the design process.

\section{References}

Argyris, C. (2002). Double-loop learning, teaching and research. Academy of Management Education and Learning, 1 (2), 206-19.

Barley, S. R., \& Tolbert, P. S. (1997). Institutionalization and structuration: Studying the links between action and institutions. Organization Studies, 18 (1), 93-117.

Bate, P., Bevan, H., \& Robert, G. (2004). Towards a million change agents. A review of the social movement literature: Implications for largescale change in the NHS. London: NHS Modernisation Agency.

Bate, P., \& Robert, G. (2006). Experience-based design: From redesigning the system around the patient to co-designing services with the patient. Quality and Safety in Health Care, 15 (5), 307-10. https://doi.org/10.1136/qshc. 2005.016527

Becker, D., Whitley, R., Bailey, E. L., \& Drake, R. E. (2007). Long-term employment trajectories among participants with severe mental illness in supported employment. Psychiatric services, 58 (7), 922-8. 
Bettencourt, L. A., Ostrom, A. L., Brown, S. W., \& Roundtree, R. I. (2002). Client co-production in knowledge-intensive business services. California Management Review, 44 (4).

Clark, M. (2015). Co-production in mental health care. Mental Health Review Journal, 20 (4), 213-19. https://doi.org/10.1108/MHRJ-10-2015-0030

Coghlan, D. (2017). Retrieving action research as research in OD. Organization Development Journal, 35 (2), 11-15.

Crowther, R. E., Marshall, M., Bond, G. R., \& Huxley, P. (2001). Helping people with severe mental illness to obtain work: Systematic review. British Medical Journal, 322 (7280), 204-8.

Davidson, L., Bellamy, C., Guy, K., \& Miller, R. (2012). Peer support among persons with severe mental illnesses: A review of evidence and experience. World Psychiatry, 11 (2), 123-8. https://doi.org/10.1016/j.wpsyc.2012.05.009

Department of Health. (2006). A vision for change - Report of the Expert Group on Mental Health Policy. Dublin: Department of Health.

Department of Health. (2012). Value for money and policy review of disability services. Dublin: Department of Health.

Department of Health. (2014). The Irish national dementia strategy. Dublin: Department of Health.

Department of Health. (2020). Sharing the vision - A mental health policy for everyone. Dublin: Department of Health.

Drake, R. E., \& Becker, D. R. (1996). The individual placement and support model of supported employment. Psychiatric Services, 47 (5), 473.

Drake, R. E., Becker, D. R., Clark, R. E., \& Mueser, K. T. (1999). Research on the individual placement and support model of supported employment. Psychiatric Quarterly, 70 (4), 289-301.

European Commission. (2009). Report of the Ad Hoc Expert Group on the Transition from Institutional to Community-Based Care. Brussels: European Commission.

Glynn, M. A. (2000). When cymbals become symbols: Conflict over organizational identity within a symphony orchestra. Organization, 11 (3), 285-98.

Government of Ireland. (2016). Rebuilding Ireland. Dublin: The Stationery Office.

Greenwood, R., Hinings, C. R., \& Suddaby, R. (2002). Theorizing change: The role of professional associations in the transformation of institutionalized fields. Academy of Management Journal, 45 (1), 58-80.

Greenwood, R. M. (2015). Evaluation of Dublin Housing First Demonstration Project: Summary of findings. Dublin: Dublin Regional Homeless Executive. https://doi.org/10.13140/RG.2.1.2588.2723

Grint, K. (2005). Problems, problems, problems: The social construction of 'leadership'. Human Relations, 58 (11), 1467-94. https://doi.org/10.1177/ 0018726705061314 
Healthcare Commission. (2005). The state of healthcare. Retrieved from https://webarchive.nationalarchives.gov.uk/20060905042930/http://www.he althcarecommission.org.uk/nationalfindings/stateofhealthcare.cfm $\quad[20$ November 2020].

Health Service Executive. (2011). Time to move on from congregated settings: A strategy for community inclusion. Report of the Working Group on Congregated Settings. Dublin: Health Service Executive.

Heifetz, R. (1994). Leadership without easy answers. Cambridge, MA: Harvard University Press.

Heifetz, R., \& Laurie, D. (2001, December). The work of leadership. Harvard Business Review.

Knapp, M., Patel, A., Curran, C., Latimer, E., Catty, J., Becker, T.,... \& Burns, T. (2013). Supported employment: Cost-effectiveness across six European sites. World Psychiatry, 12 (1), 60-8. https://doi.org/10.1002/wps.20017

Latimer, E. A., Rabouin, D., Cao, Z., Ly, A., Powell, G., Adair, C. E.,... \& Veldhuizen, S. R. (2019). Cost-effectiveness of Housing First intervention with intensive case management compared with treatment as usual for homeless adults with mental illness: Secondary analysis of a randomized clinical trial. JAMA Network Open, 2 (8), e199782. https://doi.org/10.1001/ jamanetworkopen.2019.9782

Lawrence, T. B., Suddaby, R., \& Leca, B. (2009). Introduction: Theorizing and studying institutional work. In T. B. Lawrence, R. Suddaby \& B. Leca (Eds), Institutional work (pp. 1-27). Cambridge, UK: Cambridge University Press.

Marsh, D. R., Schroeder, D. G., Dearden, K. A., Sternin, J., \& Sternin, M. (2004). The power of positive deviance. British Medical Journal, 329 (7475), 1177-9. https://doi.org/10.1136/bmj.329.7475.1177

McConkey, R., Bunting, B., Ferry, F., Garcia-Iriarte, E., \& Stevens, R. (2013). An evaluation of personalised supports to individuals with disabilities and mental health difficulties. http://www.genio.ie/files/Evaluation Personalised_Supports_UU2013_0.pdf [16 November 2020].

Mueser, K. T., Clark, R. E., Haines, M., Drake, R. E., McHugo, G. J., Bond, G. R.,... \& Swain, K. (2004). The Hartford study of supported employment for persons with severe mental illness. Journal of Consulting and Clinical Psychology, 72 (3), 479.

Needham, C., Carr, S., Mary, Q., \& Carr, S. (2009). Co-production: An emerging evidence base for adult social care transformation [SCIE research briefing 31]. London: Social Care Institute for Excellence.

Pitt, V., Lowe, D., Hill, S., Prictor, M., Hetrick, S. E., Ryan, R., \& Berends, L. (2013). Consumer-providers of care for adult clients of statutory mental health services. Cochrane Database of Systematic Reviews, 2013 (3). https://doi.org/10.1002/14651858.CD004807.pub2

Realpe, A., \& Wallace, L. M. (2010). What is co-production? London: The Health Foundation. 
Scott, W. R., Ruef, M., Mendel, P. J., \& Caronna, C. A. (2000). Institutional change and healthcare organizations: From professional dominance to managed care. Chicago: Chicago University Press.

Weick, K. E. (1979). The social psychology of organizing. Topics in social psychology (2nd edn). Reading, Mass: Addison-Wesley.

Weick, K. E., Sutcliffe, K. M., \& Obstfeld, D. (2005). Organizing and the process of sensemaking. Organization Science, 16 (4), 409-21. https://doi.org/10.1287/orsc.1050.0133

Zietsma, C., \& Lawrence, T. B. (2010). Institutional work in the transformation of an organizational field: The interplay of boundary work and practice work. Administrative Science Quarterly, 55 (2), 189-221.

Zucker, L. G. (1991). The role of institutionalisation in cultural persistence. In W. W. Powell \& P. J. DiMaggio (Eds), The new institutionalism in organizational analysis (pp. 83-107). Chicago: Chicago University Press. 